marsten versichern, dass der Fehler, gründliches Waschen und Kneten mit Wasser vorausgesetzt, niemals auch nur annähernd den Werth von 27 Gewichtsprocenten des Plasmafaserstofies erreicht. Das von mir beobachtete Maximum betrug $5,6 \%$, sehr häufig fiel die Differenz in die Fehlergrenzen, so zwar, dass das Plus auch auf der Seite des mit Kochsalzlösung gewaschenen Fibrins lag. Dieser Einwand hat übrigens keine Bedeutung mehr, seit ich in meiner letzten Arbeit gezeigt habe ${ }^{1}$ ), dass die Faserstoffmenge im filtrirten und verdünnten Plasma durch blossen Zusatz von fibrinoplastischer Substanz um 200\% erhöht werden kann, was $\mathrm{Ham}$ marsten doch gewiss nicht auf eingeschlossenes Paraglobulin beziehen wird. Bei dieser Gelegenheit wiederhole ich, dass ich in den in der vorstehenden Arbeit angeführten Versuchen das Waschen mit Kochsalzlösung niemals versäumt habe.

\title{
Ueber quantitative Eiweissbestimmungen des Blutserum und der Milch.
}

\section{Von}

J. Puls, cand. chem., Assistenten des physiologischen Institutes zu Dorpat.

Die Eiweisskörper werden meist nach der Methode von Scherer bestimmt, obgleich ein Jeder, der sich ihrer bedient, dabei die Beobachtung machen muss, dass sie viel zu wünschen übrig lässt. Das Missliche an ihr liegt bekanntlich darin, dass das coagulirte Eiweiss nicht absolut unlöslich in Wasser ist. Dieser Uebelstand war die Ursache, dass man, um diesen so wichtigen Körper genau bestimmen zu können, verschiedene andere Methoden einschlug. Liborius²), der sie einer näheren Prüfung unterwarf, fand, dass sie alle mehr oder weniger fehlerhaft waren, nur die Bestimmung

1) D. Arch. Bd. XI. p. 541.

2) Ueber quant. Eiweissbest., Dissert., Dorpat 1871. Auch im Deutsch. Archiv f. klin. Med., Bd. X. 
des Eiweisses im Serum durch Alkohol ergab die genauesten Resultate, jedoch der hohe Gehalt seiner ausgewaschenen Niederschläge an Salzen, $10-20 \%$ der trockenen Substanz, machte sein Verfahren nicht sehr empfehlenswerth. - Dieser Nachtheil führte Heynsius ${ }^{1}$ ), der die Untersuchungen von Liborius einer Prüfung unterzog, dazu, eine neue Methode zu proponiren, nämlich die auf ihren Eiweissgehalt zu untersuchende Flüssigkeit durch Diffusion von ihren Salzen $z u$ befreien, die dialysirte Flüssigkeit einzudampfen und den Rückstand als Eiweiss in Rechnung zu bringen. Abgesehen jedoch davon, dass die Entfernbarkeit der? Extractivstoffe, die in jeder von Thieren stammenden Flüssigkeit vorhanden sind, mittelst der Diffusion keine bewiesene Thatsache ist, so bedingt die kürzlich von Alex. Schmidta) bewiesene Diffusibilität des Eiweisses, die durch Wi nog radoff ${ }^{3}$ ) ihre Bestätigung erfahren hat, einen mehr oder weniger grossen Fehler je nach der Dicke der benutzten Scheidewand. Dieser lässt sich zwar durch sehr dickes Pergamentpapier, wie Heynsius es benutzte, beseitigen, sofern er das Eiweiss betrifft, aber nicht in Hinsicht auf die Extractivstoffe. Ausserdem liegt ein misslicher Umstand im Anhaften vom Eiweisse am Papier, der dann auch einer Berücksichtigung bedürfte. Der Versuch, mittelst Alkohol das Eiweiss im Serum zu bestimmen, wurde von Alex. Schmidt ${ }^{4}$ nochmals aufgenommen, und erhielt ein ganz anderes, besseres Resultat, nämlich vollständige Fällung des Eiweisses, das von den löslichen Salzen befreit ist, die in Wasser unlöslichen dagegen zurückhält. Die näheren Bedingungen festzustellen, unter denen man am besten zu diesem Resultate kommt, war das Ziel der zunächst folgenden Untersuchungen.

\section{A. Ueber die Bestimmnng des Eiweisses im Serum.}

I. Bestimmung des Eiweisses im Serum durch Alkohol.

Vor Allem suchte ich festzustellen, wie viel Alkohol zum Gelingen der Bestimmung nöthig sei, denn die von einzelnen Forschern angewandten Mengen sind sehr verschieden oder sind gar nicht er-

1) D. Archiv Bd. X, p. 244.

2) D. Archiv Bd. XI, p. 15 etc.

3) D. Archiv Bd. XI, p. 607.

4) 1. c. p. 10 . 
wähnt. In Betreff des Alkohols, der zur Coagulation diente, lag kein Grund zur Befürchtung vor, man müsse einen zu hohen Gehalt meiden; wohl aber ist dieses mit dem Alkohol der Fall, der zum Auswaschen des Niederschlages benutzt wird, denn wenn der Procentgehalt desselben sehr hoch genommen ist, so liegt die Möglichkeit nahe, dass das Auswaschen vor völlig gelungener Entfernung der löslichen Salze unterbrochen wird. Es war demnach festzustellen, welches der niedrigste Procentgehalt des Alkohols sein könne, bei welchem die Coagulation noch eine vollkommene ist, und mit welchem das Auswaschen am geeignetsten vorgenommen wird, um die löslichen Salze so schnell als möglich zu entfernen. Um Missverständnissen vorzubeugen, will ich hervorheben, dass ich hierbei durchaus nicht von der Ansicht ausging, man dürfe z. B. mit Alkohol von $90 \%$ nicht die Coagulation und das Auswaschen vornehmen, weil dann das völlige Entfernen der Salze nicht möglich sei, sondern nur die Schwierigkeit, mit der dieses dann ausführbar sei, war der Grund, die Grenze zu bestimmen, bis zu welcher man den Alkohol mit Wasser verdünnen könne, ohne Beeinträchtigung des Resultates. $\mathrm{Zu}$ allen Versuchen der folgenden Reihe bediente ich mich desselben Serum, das durch Aufbewahren bei einer Temperatur von $0^{0}$ in der kurzen Zeit, während welcher die Analysen gemacht wurden, vor jeder Zersetzung bewahrt war. Die zu jeder Analyse abgewogene Menge, ungefähr 10 Gramm, wurde mit Essigsäure bis zum Verschwinden der amphoteren Reaction und dann mit einer bestimmten Menge Alkohol versetzt. Darauf wurde nach Alex. Schmidt's ${ }^{1}$ ) Vorschlage das Gemenge zum Sieden erhitzt, worauf sich der Niederschlag gut und schnell absetzt, der dann mit Alkohol von einem gewissen Gehalte ausgewaschen wird. Nachdem dann der Niederschlag mit absolutem Alkohole und darauf mit Aether völlig extrahirt war, wurde er bei $120^{\circ}$ getrocknet, bis zum Gleichbleiben des Gewichtes gewogen, verascht, die in Wasser löslichen und unlöslichen Salze bestimmt, und durch Abzug vom Gesammtgewichte des Niederschlages die Eiweissmenge berechnet.

So wurde folgende Versuchsreihe angestellt:

1) 1. c. p. 10 . 
Ueber quantitative Eiweissbestimmungen des Blutserum und der Milch. 179 100 Theile Serum enthalten:

Tabelle I.

\begin{tabular}{|c|c|c|c|c|}
\hline $\begin{array}{l}\text { No. der } \\
\text { Analyse. }\end{array}$ & $\begin{array}{l}\text { Fällender } \\
\text { Alkohol in } \\
\text { pCt. }\end{array}$ & $\begin{array}{l}\text { Zum Aus- } \\
\text { waschen die- } \\
\text { nender Alko- } \\
\text { hol in pCt. }\end{array}$ & Eiweiss. & $\begin{array}{c}\text { Unlösliche } \\
\text { Salze. }\end{array}$ \\
\hline $\begin{array}{l}\text { I. } \\
\text { II. } \\
\text { III. } \\
\text { IV. } \\
\text { V. } \\
\text { VI. } \\
\text { VII. } \\
\text { VIII. }\end{array}$ & $\begin{array}{l}78 \\
74 \\
72 \\
69 \\
63 \\
48\end{array}$ & 80 & $\begin{array}{l}7,92 \\
7,95 \\
7,92 \\
7,97 \\
7,96 \\
7,99 \\
7,95 \\
7,65\end{array}$ & $\begin{array}{l}0,042 \\
0,047 \\
0,043 \\
0,042 \\
0,045 \\
0,048\end{array}$ \\
\hline
\end{tabular}

Diese Tabelle bedarf weiter keiner Erklärungen, nur zum zweiten Tabellenstabe ist zu bemerken, dass sie diejenige Alkoholmenge angiebt, die bei jeder Analyse die Fällung im Vereine mit der Siedetemperatur hervorbrachte. Diese Zahlen wurden, nachdem die Eiweiss- und Wassermenge durch die Analyse ermittelt waren, auf 100 Theile des Gemisches berechnet. Die im dritten Tabellenstabe befindlichen Zahlen geben den Gehalt des Alkohols an, mit dem das Auswaschen geschah; es wurden immer 150-200 Cc. desselben dazu verwandt. - Was die 3 ersten Analysen anbetrifft, so sind sie als richtig anzunehmen, da sich in den vereinigten Filtraten kein Eiweiss nachweisen liess, worauf ich später zurückkomme. Vergleichen wir mit ihnen die übrigen Analysen, um die gesuchte Grenze festzustellen, so möchte es scheinen, dass dieselbe bei der Analyse No. VII. gefunden sei, da durch Fällung bei einem Gehalte von $63 \%$ Alkohol das Resultat nicht schlechter ausfällt als bei $78 \%$. Jedoch die erstere Menge Alkohol ist zur Bestimmung nicht zu empfehlen, denn die Fällung war eine so unvollkommene, dass die ablaufende Flüssigkeit trübe ausfiel, und das Filtriren schlecht von Statten ging. Die Grenze des Alkoholgehaltes, bei dem die Analyse gut gelinge, war demnach mit dieser Zahl überschritten, obgleich der Verlusst an Eiweiss offenbar so unbedeutend war, dass er, wie ersichtlich, das Resultat nicht beeinflusste. In weit höherem Grade gilt dieses Alles von der Analyse VIII, die ganz zu verwerfen ist.

Vergleicht man mit den ersten Analysen die von IV, $V$ und VI, so ergiebt sich keine grössere Differenz, als wie es die Beobachtungsfehler mit sich bringen. Hieraus ist der Schluss zu ziehen, 
dass die Fällung und das Auswascheu am praktischsten mit so viel Alkohol vorzunehmen ist, dass der Gehalt an absolutem Alkohol dabei $70 \%$ beträgt. Diese Zah] ist deshalb etwas höher angenommen worden, als man es nach obiger Tabelle thun könnte, weil, wenn sie hart an der Grenze, die vielleicht $66 \%$ beträgt, liegen würde, schlechte Resultate zu befürchten wären wegen Verflüchtigung des Alkohols bei zu langem unverschlossenen Stehen an der Luft, oder durch zu langes Sieden etc. Alkohol und Wasser wurden in der Menge zugesetzt, dass aus dem angewandten Serum das fünf- bis zehnfache Volumen entstand. Ueber die vom Coagulum zurückgehaltenen, in Wasser löslichen Salze ist zu bemerken, dass der bei $120^{\circ}$ getrocknete Niederschlag nur in den drei ersten Analysen 0,4-0,5\% enthielt; die Coagula von den übrigen Analysen, die mit Alkohol von $70 \%$ ausgewaschen waren, enthielten dagegen nur $0,1 \%$ lösliche Salze. Diese wären wohl auch durch längeres Auswaschen entfernt worden, wie es mir weiter unten bei der Milch gelungen ist, ein von löslichen Salzen ganz befreites Eiweiss zu erhalten. Die zurückgebliebenen löslichen Salze erwiesen sich nur als schwefelsaures Natron, das wahrscheinlich aus den letzten, besonders hartnäckig zurückgehaltenen Spuren von Chlornatrium beim Verbrennen entstanden war, indem die dabei entstehende Schwefelsäure an das Natron gebunden wird, welches beim Glühen mit organischer Substanz von seinem Chlore getrennt worden ist. Eine Chlorbestimmung, die ich in der Art vornahm, dass das Eiweiss von der Analyse VI mit chlorfreiem Kali verascht wurde etc. ergab nur eine so unbedeutende Menge Chlorsilber, dass es sich der Mühe nicht verlohnte, sie zu bestimmen. In den eingedampften und veraschten Filtraten war keine Spur von Kalk durch Oxalsäure nachzuweisen, demnach waren alle unlöslichen Salze mit dem Coagulum niedergeschlagen worden; sie bestanden aus Kalk, Magnesia und Phosphorsäure. Der Gehalt des Rinderserum an unlöslichen Salzen scheint kein constanter zu sein: so fand A lex. Schmid t ${ }^{1}$ ) auf die eben beschriebene Weise $0,091 \%$, Sertolia ) auf dieselbe Weise $0,049 \%$, ich im Mittel 0,045\%, weiter unten aber $0,033 \%$. Im Mittel also 0,05\%. Nimmt man jetzt an, dass das Serum $7 \%$ Eiweiss enthält, so sind im trockenen Niederschlage von 100 Theilen Eiweiss $0,7 \%$ unlösliche Salze enthalten, wozu noch die schwer zu

1) D. Archiv, Bd. XI, p. 16.

2) Med.-chem. Untersuch, von Hop pe-Seyler, Heft III, p. 351. 
Ueber quantitative Eiweissbestimmungen des Blutserum und der Milch. 181

entfernenden $0,1 \%$ schwefelsaures Natron $\mathrm{zu}$ rechnen wären, um anzugeben, wie viel vom Coagulum als Asche in Abzug zu bringen ist, wenn man die Bestimmung der zurückgehaltenen Salze übergehen will. Die alkoholischen Filtrate wurden eingedampft und auf Eiweiss geprüft, jedoch mit negativem Erfolge. Der getrocknete Rückstand löste sich natürlich wegen der Extraktivstoffe in Wasser nicht, jedoch entstand bei Zusatz von Alkohol und Aether meist eine klare Lösung. Dieses hätte bei Gegenwart von Eiweiss nicht der Fall sein können, da es im getrockneten Zustande vicht löslich in Wasser ist, was sogar vom sonst so sehr löslichen Alkalialbuminate gilt. Ein Mal schieden sich einige bräunliche Flocken ab, die durch Abfiltriren gesammelt und ausgewaschen wurden. Mit Aetznatron erhitzt gaben sie jedoch keine Stickstoffreaktion. Das Eiweiss ist also für diesen Alkohol von $70 \%$ unlöslich. Das Neutralisiren des freien Alkali ist wegen guter and vollständiger Fällung nöthig; man hüte sich jedoch vor dem Ansäuern, weil dann leicht die unlöslichen Salze zum Theil ins Filtrat übergehen.

\section{Vergleichung der Eiweissbestimmung durch Siedehitze etc. mit der durch Alkohol.}

Um deutlich den Vortheil der eben erörterten Methode vor der ïblichen nach Scherer hervorzuheben, galt es zu untersuchen, um wie viel die Resultate letzterer Bestimmungsart von der mittelst Alkohol abweichen. Dass eine Differenz zwischen beiden statt hat, ist schon von Liborius ${ }^{1}$ ) nachgewiesen worden, indem er fand, dass die durch Scherer's Methode erhaltenen Eiweissmengen bis zu 10 Procenten weniger betrugen im Vergleiche mit der durch Alkohol gewonnenen Menge, die $=100$ gesetzt wurde; jedoch theilt Liborius auch Analysen mit, in denen der Verlust bei Scherer's Methode nur 3 Procente beträgt, ja auch Verluste von nur 1,6 und 0,3 Procenten fand er.

Da ausserdem Liborius seine Analysen nach Scherer in der Art anstellte, dass er der Untersuchungsflüssigkeit zum Zwecke besserer Fällung einen Gehalt an Chlornatrium von $4 \%$ gab, so lag es nahe zu versuchen, ob nicht ein höherer Salzgehalt ein besseres Ergebniss zur Folge haben würde. Ich ging dabei von dem Gedanken aus, da durch dic Siedtemperatur von $100^{\circ}$ die Unlös-

1) Diss. p. 25. 
lichkeit des Eiweisses in Wasser, wenn auch nicht vollkommen, bewirkt werde, so müsse durch Erhöhung der Siedtemperatur mittelst Zusatz eines neutralen Salzes die Coagulation eine vollständigere werden. Wie wenig die Ergebnisse der Versuche diesen Erwartungen entsprachen, ergiebt folgende Analysenreihe. Dieselbe wurde mit einem neuen Rinderserum angestellt, der in 100 Theilen enthielt:

Tabelle II.

\begin{tabular}{c||c||c|c}
\hline $\begin{array}{c}\text { No. der } \\
\text { Analyse. }\end{array}$ & Fällungsart. & Eiweiss. & $\begin{array}{c}\text { Unlösliche } \\
\text { Salze. }\end{array}$ \\
\hline \hline I. & 85 pCt. Alkohol & 5,99 & 0,034 \\
II. & 70 pCt. Alkohol & 5,95 & 0,032 \\
III. & & 5,98 & - \\
IV. & 42,6 pCt. NaSO & 5,75 & 0,024 \\
V. & & 5,73 & 0,020 \\
VI. & 3 pCt. $\mathrm{NaSO}_{4}$ & $\mathbf{5 , 6 7}$ & 0,026 \\
VII. & 42,6 pCt. $\mathrm{NaSO}_{4}$ & 5,69 & 0,020 \\
VIII. & 42,35 & 0,026
\end{tabular}

Zur Reihe, die mit "Fällungsart« überschrieben ist, ist zu bemerken, dass die drei ersten Analysen mit der angegebenen Menge Alkohol in der oben beschriebenen Weise angestellt wurden. Die Analysen IV, V und VI wurden in der Art gemacht, dass das bis zur sauren Reaktion mit Essigsäure versetzte Serum mit verwittertem neutralem schwefelsauren Natron bei der Siedtemperatur gesättigt wurde, wobei das Wasser 42,65 Theile des Salzes nach Gay-Lussac löst. Nach dem Erkalten wurde das Coagulum mit heissem Wasser ausgewaschen u. s. w. Bei der Analyse VII wurde nur so viel vom Salze hinzugefügt, dass der Gehalt $3 \%$ betrug. Wie ersichtlich, bewirkte das keinen Unterschied mit den drei vorhergehenden Analysen. Wohl aber war dieses der Fall, als bei der Analyse VIII das Serum unzureichend neutralisirt war, der Niederschlag filtrirte hier auffallend schlecht und das Waschwasser war etwas getrübt, jedoch viel zu unbedeutend, um den grossen Verlust zu erklären. Vergleicht man das Mittel der für das Eiweiss erhaltenen Zahlen bei den Analysen I, II, III mit den durch die Analysen IV-VII erhaltenen Resultaten, so ergiebt sich, dass bei diesen letzteren der Verlust an Eiweiss $4,4 \%$ beträgt, wenn man die durch Alkohol gefundene Eiweissmenge gleich 100 annimmt. 
Ueber quantitative Eiweissbestimmungen des Blutserum und der Milch. 183

Ebenso scheint der Gehalt des Niederschlages an in Wasser unlöslichen Salzen constant um $0,01 \%$ geringer zu sein, als bei der Bestimmung mit Alkohol.

Aus allen diesen Untersuchungen über das Serum geht hervor, dass sich das Eiweiss mit Alkohol von 70\% gut bestimmen lässt, wobei man den Vortheil hat, die Trennung der löslichen von den unlöslichen Salzen zu bewerkstelligen, da die letzteren im Niederschlage enthalten sind.

\section{B. Ueber die Bestimmung des Eiweisses in der Milch.}

Um die eben beschriebene Methode der Bestimmung durch Alkohol weiter zu prüfen, und dieselbe auf andere Eiweiss enthaltende Flüssigkeiten auszudehnen, wurde zum weiteren Untersuchungsobjecte die Milch gewählt. Die sich sehr widersprechenden Zahlen, die für den Eiweissgehalt der Milch von verschiedenen Thierklassen angegeben werden, gaben Grund genug, an der Vollkommenheit der angewandten Methoden zu zweifeln. Von den Mängeln, die den indirecten Methoden anhängen, gar nicht zu sprechen, obwohl nach denselben leider die meisten Bestimmungen gemacht worden sind, will ich nur bemerken, dass die Methode von Hoppe-Seyler ${ }^{\text {) }}$ insofern kein genaues Resultat geben kann, als die Albuminstoffe in säurehaltigem Wasser nicht völlig unlöslich sind, und dass ferner die Bestimmungsart, durch Siedehitze bei Zusatz von Essigsäure und einem neutralen Salze, welcher Brunner ${ }^{2}$ ) sich bei seinen Analysen der Frauenmilch bediente, in mir wenigstens so viel Zweifel an ihrer Vollkommenheit erregte, wie meine obigen Beobachtungen bei der Untersuchung von Serum mir Grund gaben.

I. Ueber die Methoden der Eiweissbestimmung an $\mathrm{Kuhmilch}$.

Die zu allen folgenden Analysen dienende Kuhmilch war ganz frisch, nach 24 stündigem Stehen wurde sie abgerahmt, um es nicht mit zu viel Fett zu thun zu haben, und dann wurden sofort die einzelnen Proben zu jeder Analyse, immer 10-11 Gramme, in solcher Anzahl abgewogen, dass es später nicht mehr nöthig war, neue

1) Hop pe-Seyler's Handbuch der physiol.-path.-chem. Analyse, 3. Aufl. p. 367.

2) Pflüger's Archiv, Bd. VII, p. 445. 
Portion der Milch zu entnehmen, die dann noch eine beträchtliche Schicht Rahm abgesetzt hatte. Ich that dieses deshalb, weil ich es mir nicht zutraute, durch noch so heftiges Schütteln der Milch eine ebenso feine Emulsion wie die ursprüngliche herzustellen, ein Umstand, der bei entscheidenden Fettbestimmungen, oder bei Analysen, in denen Eiweiss und Fett zusammen bestimmt werden, zu berücksichtigen wäre. Die Milch wurde bei einer $0^{0}$ nahen Temperatur aufbewahrt, bei der man wenigstens eine Woche lang die Säuerung völlig hinhalten kann, im Laufe derselben waren alle Analysen so weit in Arbeit genommen, dass Zersetzungen nicht mehr zu befürchten waren.

1) Nach der Methode von Brunner.

Die Untersuchungen wurden mit der Methode von Brunner begonnen. Da er ein so grosses Gewicht darauf zu setzen scheint, dass die Milch genau peutralisirt werde, so befleissigte ich mich durch Zusatz einer ganz verdünnten Essigsäure eine nach beiden Richtungen gleiche amphotere Reaction zu erzielen. Dann setzte ich die Menge von fast entwässertem schwefelsauren Natron hinzu, die das Wasser beim Sieden za lösen vermochte, nach dem Erkalten wurde der Niederschlag mit Wasser ausgewaschen, bis keine Schwefelsäurereaction zu erhalten war, hierauf bei $100^{\circ}$ getrocknet und mit ihm wie beim Serum verfahren.

Nach Abzug des Fettes, dessen Bestimmung später folgt, wurden so folgende gar nicht übercinstimmende Resultate erhalten:

Tabelle III:

\begin{tabular}{c||cc}
\hline I. & 0,86 & pCt. Eiweiss. \\
II. & 1,81, & $\$$ \\
III. & $2,06 \%$
\end{tabular}

Schon ehe diese Analysen beendigt waren, war ich von dem Misslingen derselben überzeugt, denn nicht nur gaben die zuletzt ablaufenden Tropfen des Waschwassers eine sehr starke Xanthoproteïnreaction, sondern auch das Filtrat schied immer beim Eindampfen eine sehr bedeutende Menge von einer braunen Substanz $a b$, die offenbar für Eiweiss $\mathrm{zu}$ halten ist, obgleich weiter keine Reactionen mit ihr anzustellen waren, als Stickstoff aus ihr in grosser Menge zu entwickeln. Die Versuche, diese gebräunte Substanz durch Trocknen bei $100^{\circ}$ so unlöslich zu machen, dass sie sich durch Auswaschen mit heissem Wasser von den Salzen und 
vom Zucker befreien liesse, misslangen deshalb, weil die Substanz schnell so aufquoll, dass die Filtration ins Stocken gerieth, ehe auch nur der kleinste Theil Zucker entfernt war.

$\mathrm{Zu}$ obigen drei Analysen ist hinzuzufügen; dass die Filtration schnell und gut von Statten ging, nur bei der ersten trübte sich das Waschwasser ganz unbedeutend. Mit der am Serum gemachten Erfahrung, dass die Eiweissbestimmung schlecht ausfällt, wenn das freie Alkali nicht genügend neutralisirt ist, erklärte ich mir das so schlecht ausgefallene Resultat. Betrachten wir das Verfahren des Neutralisirens etwas näher, so werden meine Befürchtungen verständlicher werden. Brunner ${ }^{1}$ ) versetzt die Milch so lange mit verdünnter Essigsäure, bis beim Sieden mdie alkalische Reaction eben zum Verschwinden gebracht war.« Ich habe darunter das Erreichen der amphoteren Reaction verstanden, die immer, wie hier, bei Gegenwart mehrbasischer phosphorsaurer Salze etc, auftritt, denn dieselbe folgt auf das Verschwinden der alkalischen Reaction. Ist dieses geschehen, so kann man je nach den Umständen eine nicht unbedeutende Menge einer ganz verdünnten Säure zusetzen, ohne dass die Lösung sauer reagirt. Bei diesem Punkte der Neutralisation, der selbstverständlich sehr schwer immer mit derselben Genauigkeit zu treffen ist, habe ich die drei besprochenen Analysen ausgeführt, die nicht nur für gute Kuhmilch so schlechte Resultate, sondern auch gar nicht übereinstimmende Zahlen ergaben. Dieselben sind natürlich deshalb so ausgefallen, weil das Auswaschen dieses in Wasser so löslichen Eiweisses nicht mit genau derselben Menge Wasser vorgenommen war, zum Theil mag auch der nicht bis auf das Minimum gleiche Zusatz an Essigsäure von Bedeutung gewesen sein. Die weiteren Untersuchungen und Folgerungen, die noch an diese Methode zu schliessen wären, sollen bei der Untersuchung der Frauenmilch weiter unten erfolgen.

2) Nach der Methode mittelst Alkohol.

Der einzige, der bis jetzt die Bestimmung der Milch mit Alkohol in einigen Analysen versucht hat, ist Tol mats cheff ${ }^{2}$ ), aber seine Arbeit, die alle näheren Angaben in Betreff der Ausführung der Methode entbehrt, ist in der That nicht zur sofortigen Nachfolge auffordernd. Vor Allem überzeugte ich mich, wie es mit der Lös-

1) 1. c. p. 445 .

2) Med.-chem. Untersuçh. v. Hoppe-S eyler, Heft II, p. 273. 
lichkeit des Milchzuckers in Alkohol bestellt ist, eine Frage, die Tolmatscheff keines Wortes würdigt, und die Brunner ${ }^{1}$ ) in Folge dessen abschreckte, sich der betreffenden Methode zu bedienen. Hinreichende Ursache hierzu geben alle Handbücher (GrahamOtto, Gmelin ${ }^{2}$ ) etc.), die den Milchzucker für unlöslich in Alkohol erklären. Die Versuche in dieser Beziehung wurden so angestellt, dass Alkohol von 70\% mit trockenem Milchzucker versetzt wurde, den ich zuvor durch Fällung mittelst Alkohol aus wässeriger Lösung von jeder Verunreinigung befreit hatte. Nachdem diese Mischung 24 Stunden in einem gut verschlossenen Gefässe bei $42^{\circ}$ digerirt worden war, wurde sie schnell abfiltrirt, eingedampft, bei $130^{\circ}$ getrocknet und gewogen. Bei der Bestimmung der Löslichkeit bei $16^{\circ}$ wurde die Mischung zuerst auf $42^{\circ}$ längere Zeit erwärmt und dann eine Woche lang bei Zimmertemperatnr stehen gelassen. Es ergab sich so, dass 1 Theil Milchzucker bei $16^{\circ}$ allerdings 323 Theile Alkohol von $70 \%$ zur Lösung braucht, bei $42^{\circ}$ dagegen nur 100 Theile. Diese Thatsache bietet Aussichten auf die Möglichkeit, den Zucker vom Eiweissniederschlage trennen zu können.

Die Fällung mit Alkohol geschah in der Art, dass die abgewogene Milch, nachdem sie durch Zusatz von Essigsäure die amphotere Reaction fast verloren hatte, mit ungefähr dem zehnfachen Volumen an Alkohol und Wasser so übergossen wurde, dass das Gemenge 70\% Alkohol enthält. Hierauf zum Sieden erhitzt, ist der Niederschlag, nachdem das Fett beim Erkalten sich wieder ausgeschieden hat, sofort gut filtrirbar. Nach Entfernung des AJkohol wurde der Niederschlag zuvor vom Fette befreit. Dieses geschah am zweckmässigsten, indem der Niederschlag im Becherglase, wohin man ihn zurückbringt, mit Aether digerirt wird, den man vielfach erneuert. Schliesslich wird mit Aether völlig ausgewaschen. Dann beginnt die Extraction des Milchzuckers mit siedendem Alkohol von $70 \%$ unter möglichster Vermeidung der Abkühlung. Die einzige Sicherheit, dass die letzten Spuren von Zucker entfernt sind, sehe ich allein darin, dass zwei gleich grosse Niederschläge, die mit verschieden grossen Mengen Alkohol ausgewaschen sind, das gleiche Resultat ergeben. Die Niederschläge wurden bei $120^{\circ}$ getrocknet, gewogen und der Gehalt an Salzen durch Veraschen bestimut. So wurden folgende auf 100 Theile Milch bezogene Resultate erhalten:

1) 1. c. p. 444.

2) Le op. Gmelin's Handbuch, 4. Auflage, Bd. VIl, p. 669. 
Ueber quantitative Eiweissbestimmungen des Blutserum und der Milch. 187

Tabelle IV.

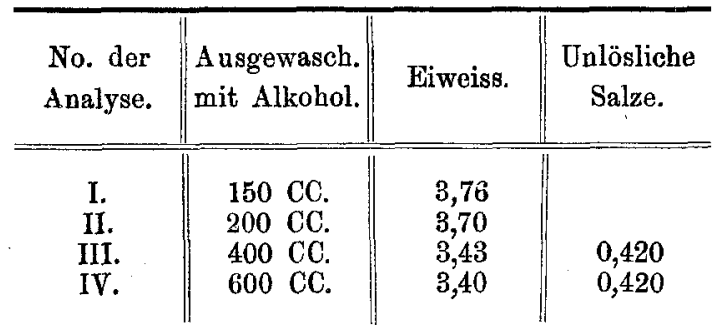

Wie man sieht waren die beiden Analysen I und II noch nicht genügend ausgewaschen worden, die in dem zweiten Tabellenstabe angegebene Alkoholmenge hatte also hier noch nicht alles Entfernbare extrahirt. Wohl war aber dieses bei Nr. III $u$. IV der Fall, die beide als vollendet anzusehen sind, denn sonst hätte die um $200 \mathrm{Cc}$. grössere Alkoholmenge eine andere Differenz ergeben müssen. Das Eiweiss von No.I wurde mit heissem Wasser behandelt, um aus ihm den Zucker zu extrahiren und denselben nachzuweisen, jedoch gelang es nicht, da zugleich etwas Eiweiss sich löste, das die Reaction störte.

Das Eiweiss von No. II ergab mit Aetzkali verbrannt etc. nur einige Zehntel Milligramme AgCl. Es konnte daher angenommen werden, dass in den beiden Analysen III und IV alles Chlorkalium etc. entfernt war; sie enthielten auch in der That keine löslichen Salze.

3) Nach der Methode von Hoppe-Seyler.

Diese Methode wurde in der Art angewandt, dass 11 Gramme Milch mit 190 Cc. Wasser, und dann mit 0,7 Cc. einer $0,25 \%$ Essigsäure enthaltenden Lösung versetzt und schliesslich mit Kohlensäure gesättigt wurden. Da nach 12 Stunden langem Stehen die Fällung noch nicht eingetreten war, so wurden noch $0,3 \mathrm{Cc}$. von derselben Essigsäure hinzugefügt, worauf die Fällung sofort eintrat. Im Filtrate wurde dann das Albumin durch die Siedtemperatur in den unlöslichen Zustand übergeführt und so bestimmt. Es ergaben so zwei in derselben Art angestellte Analysen, dass 100 Theile dieser Kuhmilch enthalten:

\begin{tabular}{c||c||c|c}
\multicolumn{4}{c||}{ Tabelle V. } \\
\hline $\begin{array}{c}\text { No. der } \\
\text { Analyse. }\end{array}$ & Caseïn. & Albumin. & $\begin{array}{c}\text { Eiweiss in } \\
\text { Summa. }\end{array}$ \\
\hline I. & $\begin{array}{c}2,70 \\
2,64\end{array}$ & $\begin{array}{c}0,53 \\
0,54\end{array}$ & $\begin{array}{c}3,23 \\
3,18\end{array}$
\end{tabular}


Die hier erhaltenen Zahlen für das gesammte Eiweiss sind demnach um $0,2 \%$ zu klein ausgefallen im Vergleiche mit den nach der vorhergehenden Methode bestimmten. Diese Differenz musste vermuthet werden, denn im Filtrate vom Caseïn liess sich das Albumin nicht völlig ausfällen, sondern ich erhielt nach dem Abfiltriren desselben immer noch Eiweissreactionen. Letzteres war bei dieser Methode zu erwarten, da dieselbe mit dem Fehler verknüpft ist, dass man als Fällungsmittel eine Säure hinzufügen muss, die im Ueberschusse ein Lösungsmittel für das Caseïn und andere Albuminate ist. Hoppe-Seyler fügt, um dieser Gefahr zu entgehen, "sehr verdünnte Essigsäure tropfenweise hinzu“ etc., bis nach Stunden und Tagen die Fällung eingetreten ist. Doch scheint es mir, dass bei dieser Methode so lange nicht unbedeutende Fehler gemacht werden können, bis der Zusatz der Säure schärfer bestimmt worden ist. Dieses jedoch mag seine Schwierigkeit wegen des schwankenden Gehaltes an Alkali haben, auf den man aus den Angaben verschiedener Autoren schliessen muss, die der Milch bald alkalische (Vernois et Becquerel etc.), bald amphotere (Soxhlet), ja sogar auch saure Reaction zuschreiben.

Ueber die Fettbestimmungen der Kuhmileh.

Da meine Untersuchungen es mit sich brachten, nicht nur das Fett genau zu bestimmen, sondern auch das Eiweiss völlig vom Fette zu befreien, so sehe ich mich genöthigt, meine Ansichten und Beobachtungen über die Methoden der Fettbestimmung auszusprechen, über welche in den letzten Jahren eine so lebhafte Discussion entbrannt ist. Den Grund zu derselben gab Brunner, der in seiner Arbeit 1) das überraschende Resultat brachte, dass normale Frauenmilch im Mittel einen Gehalt an Fett von $1,73 \%$ habe. Brunner bediente sich dabei der Methode von Trommer ${ }^{2}$ ), die darin besteht, dass Mich mit gepulvertem Marmor getrocknet, zerrieben und mit Aether extrahirt wird. Gegen diese Methode erhob Schukowsky ${ }^{3}$ ) Bedenken auf Grund mehrerer Analysen nach seiner Methode, die ihm 3\% Fett als den normalen Gehalt der Frauenmilch ergaben. Seine Methode ${ }^{4}$ ) beruht darauf, dass er das Fett durch Alkohol und Aether der Milch entzieht, das eingedampfte

1) l. c. p. 453 .

2) Schmidt's Jahrbücher, Bd. 107, p. 291.

3) Zeitschr. f. Biologie, Bd. IX, p. 432.

4) Ber. d. deutsch.-chem. Gesellsch. z. Berlin, Bd. V, p. 76. 
Fitrat durch Wasser und Aether löst und die ätherische Schicht durch den Scheidetrichter trennt. Die Genauigkeit der Bestimmung nach Trommer bezweifelt er wegen der Unmöglichkeit, dem Marmor alles Fett durch Aether zu entziehen, ohne für die letztere Behauptung experimentelle Beweise anzuführen. Un diesen Streit zu entscheiden, machte Löwit ${ }^{1}$ ) Fettbestimmungen an derselben Milch nach obigen beiden Methoden und zur Controle noch nach einer dritten von Hoppe-Seyler ${ }^{2}$ ), die darin besteht, dass man einer mit Aetznatron versetzten Milch das Fett durch Schütteln mit Aether entzieht.

Durch die erste und die letzte Methode fand Löwit übereinstimmende Resultate, die von Schuk ow sky dagegen gab $0,1-0,2 \%$ Fett zu wenig. Den Grund hiervon sieht Löwit in der Unmöglichkeit, dem Eiweiss, das durch Alkohol gefällt ist, das Fett durch Aether völlig zu entziehen, dieses sei erst möglich, wenn der Niederschlag mit Natronlauge behandelt sei. Zweifel an der Richtigkeit dieser Behauptung erregten mir die von $\mathrm{L} \ddot{0}$ wit gerade als Beweise angeführten Zahlen für das Fett, das er nachträglich auf die eben beschriebene Weise dem Coagulum entzog. Er fand so in vier verschiedenen Niederschlägen von 100 Milch 0,$0535 ; 0,0111$; 0,$0305 ; 0,0110 \mathrm{Fett}^{3}$ ). Ich denke, dieser wechselnde Fettgehalt ndes Eiweissniederschlages sammt Filter « zeigt deutlich, dass hier noch andere Umstände als die Unmöglichkeit, dem Eiweiss alles Fett zu entziehen, im Spiele gewesen sind. Ich bin jedoch weit entfernt, die Methode von Schukowsky zu vertheidigen, in der Theorie derselben sehe ich zwar keine Fehlerquellen, sondern nur in der praktischen Ausführung, denn die Manipulationen mit dem Scheidetrichter können die Resultate wohl sehr schwankend machen.

Auf diese Untersuchungen eingehen $\mathrm{zu}$ müssen, glaubte ich deshalb, weil es für meine Eiweissbestimmungen von der grössten Bedeutung ist, die Behauptung, dass das Eiweiss von dem Fett nicht zu trennen sei, zu widerlegen. Ich habe daher die betreffenden Versuche Löwits mit dem Eiweissniederschlage wiederholt, konnte aber nicht die geringste Spur Fett aus ihnen extrahiren, sondern nur Natron, das beim Erhitzen sich etwas bräunlich färbte,

1) D. Archiv Bd. X, p. 65.

2) Handbuch der physiol.-path.-chem. Analyse, 3. Aufl., p. 369.

3) Um diese Zahlen mit einander vergleichen za können, habe ich dieselben aus den angegebenen Daten berechnet. 
ging ins Extrakt über, aus dem der Aether nichts ausziehen konnte, da er eben nur aus Natron bestand.

Aber besser noch als durch diese Versuche kann ich durch meine Fettbestimmungen selbst den Beweis für die Möglichkeit liefern, dass das Fett durch Alkohol und Aether vom Caseïn zu trennen sei. Ich vereinigte diese Bestimmungen mit denen des Eiweisses durch Alkohol, die unter Tabelle IV angegeben sind, indem die dabei erhaltenen alkoholisch-ätherischen Filtrate, die alles Fett und Zucker etc. enthalten, dazu benutzt wurden. In Betreff der Entziehbarkeit des Fettes wäre dabei darauf aufmerksam zu machen, dass wenn auch einige Spuren von Fett wie bei Löwit durch Aether noch nicht entfernt wären, dieses durch die grosse Menge von heissem Alkohol sicherlich geschehen kann, mit welchen der so überaus fein vertheilte Niederschlag später behufs Entfernung des Zuckers behandelt wurde. Das so erhaltene Filtrat wurde eingedampft, der getrocknete Rückstand möglichst durch Aether vom Fette befreit, dann vollständig getrocknet und so fein pulverisirt, dass der Aether leicht die fein vertheilte Masse zu durchdringen vermochte. Dieses so gewonnene Fett enthält noch etwas Zucker, der wahrscheinlich durch das noch nicht völlig ausgetriebene Wasser gelöst worden war, daher wurde dieses Fett nach völligem Trocknen nochmals in Aether gelöst, abfiltrirt, etc. So wurde ein in der Wärme völlig klares, hellgelbes Fett erhalten. Drei in dieser Art ausgeführte Bestimmungen ergaben für die oben benutzte Kuhmilch: 2,$63 ; 2,58 ; 2,58 \%$ Fett.

Um diese Zahlen controliren zu können, mussten Bestimmungen nach einer anderen Methode gemacht werden, wozu ich die von Trommer wählte. Streng seinen Vorschriften folgend, nur wandte ich viel mehr Aether an als er ${ }^{1}$ ), fand ich Resultate, die mit $0,2-0,3 \%$ hinter den eben mitgetheilten zurückblieben. Zwei Möglichkeiten lagen vor, welche die Ursache dieses zu klein ausgefallenen Resultates sein konnten. Entweder war der Rückstand noch nicht genügend mit Aether ausgezogen worden, oder er war nicht weiter extrahirbar. Die erstere prüfend, fand ich, dass durch 100 Cc. Aether noch 0,1\% Fett gewonnen werden konnten. Die

1) Das Original war mir nicht zugänglich, aus dem Referate in Schmidt's Jahrbüchern Bd. 107, p. 291 musste jch jedoch annehmen, dass Trommer 50 Gramm Milch mit 30 Gramm Marmor eindampft und dann mit 25-30 (?) Gramm Aether entfettet. 
Ursache, dass diese Menge Fett nicht zuvor schon entzogen war, lag daran, dass ich, wie gewöhnlich, in einem Urglase den zuletzt abtropfenden Aether aufgefangen hatte, der nach dem Verdunsten einen so unbedeutenden Rückstand hinterliess, dass er für das Auge und die Wage nicht wahrnehmbar war, woraus ich schloss, dass die Extraction vollendet sei. Wie dieser Versuch es zeigte, ist das aber nicht so leicht der Fall, sondern man muss vielmehr auf die letzten Centigramme Fett keinen Aether und keine Mühe sparen, um sie dem Rückstande zu entziehen. Jedoch durch noch weiteres Behandeln mit Aether konnte kein Fett mehr entzogen werden, obgleich noch $0,1 \%$ Fett fehlte. Demnach waren also die obigen drei Fettbestimmungen zu hoch ausgefallen, oder Schukowsky's Behauptung, der Marmor hindere die völlige Fettextraction, war begrünỏet.

$\mathrm{Zu}$ sicher jedoch darin, dass meine Bestimmungsart des Fettes weder in den theoretischen Voraussetzungen, noch in der Ausführung einen Fehler involvire, musste ich denselben in dem energischen Zurückgehaltenwerden des Fettes bei der Methode von Trommer suchen. Dass aber der so sehr poröse Marmor hierbei der Schuldige sei, konnte ich mir nicht vorstellen, sondern ich suchte den Grund in Folgendem: Nach Trommer's Angaben hatte ich auf $10 \mathrm{Gr}$. Milch 6 Gr. Marmurpulver genommen. Bei diesem Verhältuisse ist ein grosser Theil der Milch nicht in Berührung mit dem Pulver, lässt man jetzt, wie ich es that, das Ganze ungestört eindampfen, so bildet sich an der Oberfläche die Haut von Eiweiss, die, allmählich immer dicker werdend, einiges Fett entschieden einschliesst. Trocknet man schliesslich noch das Ganze, so erhält die oberste Schicht eine Hornconsistenz, durch welche sie das feine Zerreiben verhindert, und für Aether nicht zu durchdringen ist.

Um diese Voraussetzung zu prüfen, mischte ich zwei neue Proben derselben Milch mit etwa dem gleichen Gewichte an Marmor und dampfte unter fortwährendem Umrühren dieselben ein. Nachdem sie eine ziemlich feste Consistenz erhalten hatten, zerrieb ich sie, was dann noch leicht von Statten ging, und trocknete jetzt das Pulver voliständig bei $100^{\circ}$, bis alles Wasser entfernt war, dann wurde das Pulver so lange mit Aether behandelt, bis wenigstens $50 \mathrm{Cc}$. keinen wägbaren Rückstand hinterliessen; um diesen Punkt zu erreichen, brauchte ich wenigstens $300 \mathrm{Cc}$. Aether auf $10 \mathrm{Gr}$. Milch. Nach dem Trocknen bei $100^{\circ}$ wurden so folgende Resultate erhalten: 
$2,57 \%$ und 2,62\% Fett, Zahlen die mit den vorhergehenden gut übereinstimmen.

Hieraus folgt, dass unter Beobachtung der eben angegebenen Vorsichtsmassregeln die Methode von Trommer zu empfehlen ist, die dann ebenso gute Resultate ergiebt, wie wenn man durch Alkohol gefälltem Eiweiss mit Aether das Fett entzieht. Dass dieses vollständig von Statten gehen muss, ist ein nothwendiges Erforderniss, ohne das kein übereinstimmendes Resultat mit Bestimmungen nach anderen Methoden zu erwarten wäre.

Uebrigens steht diese Ansicht über die Entziehbarkeit des Fettes nicht vereinzelt da, sondern Hoppe-Seyler ${ }^{1}$ ) erwähnt bei seiner Bestimmungsart des Eiweisses in der Kuhmilch, man könne das mitgefällte Fett durch Aether trennen und so zugleich bestimmen. Ein Versuch, den ich in dieser Art anstellte, gab mir das gute Resultat von 2,59\% Fett. Mag man nun auch mit Recht einwenden, dass das durch Alkohol gefällte Eiweiss viel fester coagulirt ist, als das durch Essigsäure niedergeschlagene, so muss ich doch hervorheben, dass das Letztere im Vergleiche zum Ersteren sehr grobflockig ist.

Der Uebersicht wegen stelle ich die Resultate der Fettbestimmungen in folgender Tabelle zusanmen:

Tabelle VI.

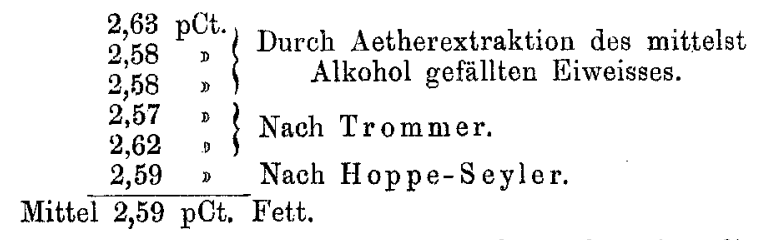

Das Uebereinstimmen dieser Zahlen beweist die Richtigkeit der oben auseinander gesetzten Behauptungen.

II. Ueber die Methoden der Eiweissbestimmung an Frauenmilch.

Zum Schlusse prüfte ich die Methode der Alkoholfällung an Frauenmilch, für die es mir ganz besonders erforderlich schien, einen neuen Weg der Eiweissbestimmung zu finden, um die von

1) Handbuch der physiol.-path.-chem. Analyse von Hoppe-Seyler, 3. Auflage, p. 367 . 
Ueber quantitative Eiweissbestimmungen des Blutserum und der Milch. 193

Brunner erlangten Zahlen controliren zu können, denn von der Unmöglichkeit, die Methode von Hop pe-Seyler an ihr durchzuführen, habe ich mich auch äberzeugt. Zwar liess sich die wie oben nach dieser Methode behandelte Milch anfangs mässig schnell filtriren, jedoch bald wurde das Ablaufen des Wassers immer langsamer und hörte schliesslich völlig auf.

Brunner ${ }^{1}$ ) kam bei seinen Untersuchungen zum unerwarteten Resultate, dass normale Frauenmilch $0,63 \%$ Eiweissverbindungen enthalte. (Mittel aus 18 Analysen, bei Grenzwerthen von $0,15-1,5 \%$.) Diese erhebliche Abweichung von den bis dahin bekannten Zahlen erklärt Brunner theils durch die Vorzüge seiner Methode, theils schreibt er sie dem Umstande zu, dass er die Milch von Frauen nahm, die schon seit mehreren Monaten entbunden waren, während sonst die Milch immer gleich in den ersten Wochen des. Stillens zur Untersuchung genommen ist.

Deshalb verschaffte ich mir auch die Milch von einer Frau, die 101/2 Monate einen Säugling ernährt hatte. Sie war 22 Jahre alt, erstgebärend, von selten robuster Constitution. Die Abscheidung der Milch wurde, um Betrug zu vermeiden, in meiner Anwesenheit vorgenommen, und zwar wurden ein Drittheil am Abende, einige Stunden nach dem letzten Stillen, das übrige am nächsten Morgen secernirt. Die Milch reagirte deutlich alkalisch und war von gewöhnlichem weissen Aussehen. Das Aufbewahren und Abwiegen geschah wie bei der Kuhmilch, nur mit dem Unterschiede, dass die Frauenmilch nicht abgerahmt wurde.

\section{1) Nach der Methode von Brunner.}

Die bei der Kuhmilch gemachten Erfahrungen hatten gelehrt, dass man bei dem Zusatze der Säure bis zur amphoteren Reaktion schlechte Resultate erhalte. Die damals eingetretene Zersetzung hinderte die weitere Ermittelung der etwaigen durch Ansäuern zu erhaltenden Resultate, weshalb ich die betreffenden Untersuchungen jetzt wieder aufnahm. Dieses Ziel wurde in nachstehender Tabelle verfolgt, in der die dritte Zahlenreihe angiebt, wie viel von einer 2,5\% enthaltenden Essigsäure $\mathrm{zu} 100$ Theilen Milch gefügt wurde:

1) I. o. p. 453 . 


\begin{tabular}{c||c||c}
\multicolumn{3}{c}{ Tabelle VII. } \\
\hline $\begin{array}{c}\text { No. der } \\
\text { Analysen, }\end{array}$ & $\begin{array}{c}\text { Eiweiss } \\
\text { in pCt. }\end{array}$ & Essigsäure. \\
\hline I. & 0,83 & \\
II. & 0,76 & 2,72 \\
III. & 0,87 & 3,63 \\
IV. & 0,54 & 1,82 \\
V. & 0,34 &
\end{tabular}

Die Menge Essigsäure, mit der die ersten zwei Analysen versetzt wurden, bewirkte eben eine deutliche saure Reaction nach dem Sieden, ein weiterer Zusatz wie bei No. III änderte das Resultat nicht, wohl fand dieses aber statt bei No. IV und V, bei denen die angegebene Menge Essigsäure nur eine amphotere Reaction hervorrief.

Aus diesen Untersuchungen über die Anwendbarkeit der Methode, das Eiweiss der Kuh- und Frauenmilch durch Essigsäure, schwefelsaures Natron und Siedhitze zu bestimmen, folgt, dass es dabei durchaus erforderlich ist, der Milch beim Sieden eine deutlich saure Reaction zu geben. Thut man dieses nicht, so erfolgen die schlechten Resultate wie bei der Analyse IV, V und in Tabelle III. Es muss das als eine Eigenthümlichkeit des Caseïn betrachtet werden, dass es unter diesen Umständen so löslich in Wasser ist, denn sichtbar war das Abnehmen der Eiweissmenge auf dem Filter beim Auswaschen.

Mag man auch annehmen, dass Brunner immer den von mir geforderten Punkt des Ansäuerns getroffen hatte, nur in zwei Fällen kann ich das nicht zugeben, und zwar in denen ${ }^{1}$ ), wo er zur Controle nebeu den Bestimmungen nach der von ihm angewandten Methode noch Stickstoffbestimmungen durch Glühen mit Natronkalk machte. Die in letzterer Zeit gegen diese Methode erhobenen Einwände scheinen begründete zu sein, eine solche Fehlerquelle jedoch kann sie unmöglich mit sich bringen, dass dadurch solche Differenzen, wie sie sich in Brunner's Angaben finden, erklärt werden könnten. So fand Brunner bei zwei Milchsorten nach seiner Methode $0,25 \%$ und $0,59 \%$, durch die Stickstoffbestimmung aber 1,19 resp. $1,38 \%$ Eiweiss.

Ein genaues Resultat ist aber auch beim Ansäuern nicht zu

1) 1. c. p. 446,447 . 
Ueber quantitative Eiweissbestimmungen des Blutserum und der Milch. 195

erwarten, denn das zuletzt ablaufende Filtrat giebt immer sehr deutliche Eiweissreactionen. Ich habe diese meist durch die Xanthoproteïnprobe angestellt, die den Albuminstoffen nicht allein zukommt, da sie aber immer am Schluss der Analyse vorgenommen wurde, so mussten diese anderen Stoffe doch schon entfernt sein. Besser noch als durch diese Reaction überzeugt man sich durch die bräunliche Substanz, die beim Eindampfen sich ausscheidet und in Wasser dadurch schwer löslich wird, dass diese Modification der Methode von Scherer auf die Milch nicht anwendbar ist.

2) Nach der Methode mittelst Alkohol.

Bei dieser Methode, die in der oben beschriebenen Weise ausgeführt wurde, resultirten folgende Zahlen. 100 Theile Milch enthalten:

Tabelle VIII.

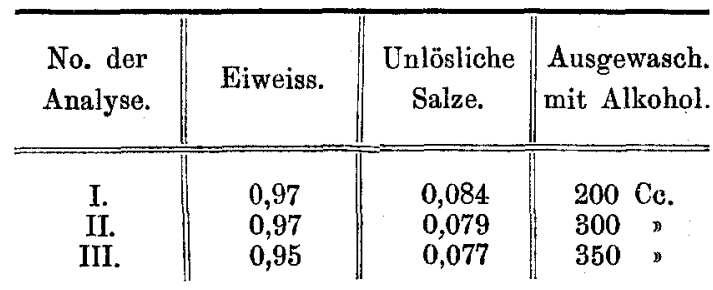

Aus diesen übereinstimmenden Resultaten sieht man, dass schon die Analyse I vollendet war, und dass durch weiteres Behandeln mit Alkohol das Eiweiss nicht vermindert wird. Eiweissreactionen gelangen mir hier mit dem Filtrate nie. Auch hier bestätigt sich das von Alex. Schmidt am Serum gefundene Resultat, dass das durch Alkohol gefällte Eiweiss die unlöslichen Salze einschliesse, es gelang mir nicht im Filtrate Kalk nachzuweisen. Es ist hierzu zu bemerken, dass der Gehalt dieser Milch an unlöslichen Salzen, die aus Kalk, Magnesia und Phosphorsäure bestanden, unbedeutend höher ist, als die Zahl, welche man erhält, wenn man die von Bung e ${ }^{1}$ ) erhaltenen Resultate für den Gehalt einer Frauenmilch an Kalk, Magnesia und Eisenoxyd als dreibasische phosphorsaure Verbindungen in Rechnung bringt. Ich berechnete so aus den von ihm gefundenen Zahlen, dass die von ihm untersuchte Milch in der einen Analyse 0,07517\% und in der anderen 0,07862\% unlösliche Phosphate enthielt. Zur Bildung von löslichen phosphorsauren Verbindungen war noch Phosphorsäure nach dieser Rechnung disponibel. Die löslichen Salze waren auch hier, da sie in der Frauenmilch so 
ganz besonders wenig vertreten sind, nach $\left.\mathrm{Bunge}{ }^{1}\right) 0,15 \%$, wie in der Kuhmilch durch die hinreichend grosse Menge Alkohol ausgewaschen worden.

In Betreff der nach den Methoden ron Hoppe-Seyler und von Brunuer erhaltenen Eiweissniederschläge von der Milch ist hervorzuheben, dass mit Ausnahme einiger Spuren von löslichen Salzen sie keinen Rückstand hinterliessen. Die unlöslichen anorganischen Bestandtheile waren immer durch das Auswaschen entfernt worden.

Die Fettbestimmung ergab 3,08\% nach Trominer, and ebenfalls 3,08\% durch Aetherextraction des mittelst Alkohol gefällten Eiweisses.

Nach Entfernung des Fettes löste sich der Rückstand in Wasser klar auf, nur einige braune Flocken schwammen in der Lösung, die aber keinen Stickstoff enthielten. Diese Lösung des Zuckers titrirte ich mit Fehling 'scher Lösung, wodurch 5,26\% Zucker erhalten wurden.

Betrachtet man die Analyse dieser Milch, die $0,97 \%$ Eiweiss, 3,08 ) Fett, 5,26 "Zucker enthält, so muss man sagen, dass Brunuer ibrigens Recht hat zu behaupten, dass die Frauenmilch mit der Zeit nach der Entbindung an Eiweissgehalt abnehme, wie es die Untersuchung der hier benutzten Milch bestätigt, welche, was hervorzuheben ist, von einer ausserordentlich kräftigen Frau producirt wurde. - In der Literatur habe ich nur von Bunge ${ }^{2}$ ) einige Analysen von Frauenmilch, die aus älterer Säugungsperiode stammte, gefunden. Er bestimmte den Stickstoffgehalt der Milch, woraus die Albuminate berechnet wurden. So ergab die Milch von einer Frau 11 Monate nach der Entbindung 1,2027\% und die von einer anderen $0,9016^{\circ} \%$ Albuminate 10 Monate nach der Geburt. Für einen niedrigen Eiweissgehalt der Milch spricht ferner die von Biedert ${ }^{3}$ ) gefundene 'Thatsache, dass elende und schwächliche Kinder mit seinem "Rahmgemenge , das $1 \%$ Eiweiss enthält, gut gediehen.

1) Zeitschrift f. Biologie Bd, X, p. 316 .

2) l. c. p. 313,316 .

3) Virchow's Archiv, Bd. LX. p. 372. 